Choi et al., Afr., J. Complement Altern Med. (2019) 16 (1): 34-40

https://doi.org/10.21010/ajtcam.v16 i1.4.

\title{
DUKKU AND BAEKAM SPRINGWATER INHIBIT THE UREASE ACTIVITY OF HELICOBACTER
} PYLORI

\section{SungSook Choi, ${ }^{1}$ HaeKyung Lee, ${ }^{2}$ JinWoo Kim, ${ }^{3}$ JiHan Yu, ${ }^{4}$ HyunHo Choi, ${ }^{4}$ HyungKeun Kim, ${ }^{4}$ SangWoo Kim, ${ }^{4}$ and Hiun Suk Chae ${ }^{4 *}$}

${ }^{1}$ College of Pharmacy, Sahmyook University, Seoul, Korea; ${ }^{2}$ Department of Laboratory Medicine Uijongbu St. Mary's Hospital, College of Medicine, The Catholic University of Korea, Seoul, Korea; ${ }^{3}$ Department of Dermatology, Uijongbu St. Mary's Hospital, College of Medicine, The Catholic University of Korea, Seoul, Korea; ${ }^{4}$ Department of Internal Medicine Uijongbu St. Mary's Hospital, College of Medicine, The Catholic University of Korea, Seoul, Korea.

"Corresponding author's E-Mail: $\underline{\text { sschoi @ syu.ac.kr }}$

\section{Article History}

Received: April, 10. 2017

Revised Received: July, 23. 2018

Accepted: July, 25. 2018

Published Online: Feb. 27, 2019

Abstract

Background: Springwater (SW) contains many kinds of minerals such as sodium, potassium and copper. These metallic ions may influence the activity of metallo-enzymes such as urease via competitive inhibition. In this study, we investigated the effect of SW on the inhibition of Ni-containing urease activity, which is essential for the colonization of Helicobacter pylori (H. pylori) in the human stomach.

Materials and Methods: We studied the growth inhibition of $\mathrm{H}$. pylori by SW. We evaluated ammonia production to detect urease activity and performed western blot analysis of UreA and UreB for enzyme production.

Results: SW had no significant effect on bacterial growth. Western blot analysis also showed that SW did not affect the translation of UreA and UreB, but it significantly reduced the urease activities of the Jack bean as well as that of $H$. pylori from 50 to $75 \%$.

Conclusion: These results might indicate that the consumption of SW may prevent the colonization of $H$. pylori and ameliorate the toxic effect on gastric mucosa via the inhibition of urease activity.

Keywords: Springwater, H. pylori, Urease activity, Western blot.

Abbreviations: SW: Spring water, H. pylori: Helicobacter pylori, KCTC: Korean Culture Collection, BHI: Brain Heart Infusion, DS: Dukku spring, BS: Baekam spring, DSW: Dukku spring water, BSW: Baekam spring water.

\section{Introduction}

Helicobacter pylori $(\mathrm{H}$. pylori) is a microaerobic, gram-negative bacilli that infects more than $70 \%$ of Koreans over the age of 40. H. pylori is closely related to upper gastrointestinal disorders such as chronic gastritis, peptic ulcer and gastric cancer (Kim et al., 2001). Many kinds of virulence factors, such as urease and adhesion, have been widely studied for their involvement in the colonization of bacteria, and these have been a target of drug development (Dunn, 1993; Graham and Yamaoka, 2000; Dunn, 1993). In particular, urease is a very important factor for survival in the strongly acidic environment of the human gastric mucosa, because it degrades urea to ammonia and carbon-dioxide $\left(\mathrm{CO}_{2}\right)$ (Marshall et al., 1990). The ammonia-producing ability of $\mathrm{H}$. pylori urease is about 100 times greater than that of the Proteus species. Moreover, the Km value of $H$. pylori urease is 10 to 20 times lower than that of Proteus sp., which means that the affinity of $\mathrm{H}$. pylori urease to urea is very strong even at very low concentrations of urea (Mobley et al., 1991; Osaki et al., 2008). The antral mucosa, the pH-sensing region of the stomach, secretes gastrin, which is neutralized by the ammonia produced by urease and then damages the phospholipids of gastric epithelial cells by activating bacterial phospholipase. Therefore, the inhibition of $H$. pylori urease activity might have been considered a target of H. pylori treatment (Khan et al., 2004; Kosikowska and Berlick, 2011; Yu et al., 2015). For example, natural products such as biscoumarine inhibit the function of urease activity (Khan et al., 2004; Lodhi et al., 2014), and metal ions can also inhibit urease function via competitive inhibition with the nickel in the enzyme (Zaborska et al., 2004). A typical metal ion, silver ion, exerts an inhibitory function by interacting with the SH group of the enzyme. SW is an abundant source of minerals, but only a few reports have focused on its effect on H. pylori and urease.

Drinking of SW has been known to increase blood flow in the gastric mucosa, to inhibit gastric emptying, and to 
change the secretion of gastric juices, depending on the type of SW (Petrakova, 2001; Bertoni et al., 2002;). Sodium bicarbonate SW has been used to neutralize gastric acid and inhibit gastric cramps. Carbonate SW is known to increase the gastric mucosal blood flow, and is used in chronic gastritis (Bertoni et al., 2002). However, studies on how SW effects $H$. pylori have been rare. The present study was performed to investigate the effect of SW on the growth of $H$. pylori and urease activity.

\section{Materials and Methods \\ Bacterial strain}

A standard strain of $H$. pylori 26695 was purchased from the Korean Culture Type Collection (KCTC, Taejeon, Korea) for use as a test strain. $\mathrm{H}$. pylori was cultured at $37{ }^{\circ} \mathrm{C}$ in a microaerobic $\left(5 \% \mathrm{O}_{2}, 10 \% \mathrm{CO}_{2}\right.$ and $85 \% \mathrm{~N}_{2}$ gas) atmosphere that is a standard for brain-heart infusion (BHI) (Difco, Detroit, MI) with 7\% laked horse blood (Oxoid, Cambridge, CB5 8BZ, UK), 0.4\% isovitalex (BBL, Sparks, MD, USA), vancomycin (6 $\mu \mathrm{g} / \mathrm{ml})$, amphotericin B (8 $\mu \mathrm{g} / \mathrm{ml})$ and trimethoprim $(5 \mu \mathrm{g} / \mathrm{ml})$. In the case of a liquid medium, $7 \%$ horse serum (Sigma Co. St. Louis, USA) was used instead of blood.

\section{Springwater and Hydrochemical analysis of spring water}

From the Dukku (DS, Buk-myeon, Uljin gun, province of Gyeongsangbuk-do, South Korea) and Baekam (BS, Onjeong-myeon. Uljin gun, province of Gyeongsangbuk-do, South Korea), samples were gathered every two weeks. These waters were filter sterilized $\left(0.45 \mu \mathrm{m}\right.$ cellulose membrane) and kept at $4{ }^{\circ} \mathrm{C}$ for 2 weeks. Hydrochemical analysis of both types of springwater was performed according to a method established by Lee (Lee et al., 2014).

\section{Inhibitory activity of SW on the growth of $\mathrm{H}$. pylori}

BHI liquid media were prepared using the Dukku (BHIDSW) and Baekam SW (BHIBSW) instead of distilled water. We inoculated the BHIDSW, BHIBSW and normal BHI (prepared with distilled water) with $10^{8}$ cells $/ \mathrm{mL}$ of $H$. pylori, followed by incubation for 3 days. After incubation, the cells were washed with PBS and then serially diluted tenfold with PBS and spotted onto BHI. Colony formations were counted after 3 days of incubation.

\section{Inhibition of Jack bean urease by spring water}

Jack bean urease (Sigma-U7752) purchased from Sigma-Aldrich (Sigma. Co. St. Louis, USA) was used for enzyme assay. $15 \mu \mathrm{l}$ of Jack bean urease $(1 \mu \mathrm{g} / \mathrm{ml}$ in $0.1 \mathrm{M}$ phosphate buffer, $\mathrm{pH} 7.4$ ) was added to $1 \mathrm{ml}$ of three different $10 \%$ urea solutions [10\% urea solution was made using distilled water, Dukku spring water (DSW) and Baekam spring water (BSW), respectively] followed by incubation at room temperature for $90 \mathrm{~min}$. During incubation, the produced ammonia was spectrophotometrically assayed using a Hitachi 7600 (Tokyo, Japan) at 30 min intervals. PBS was used as a control instead of a $10 \%$ urea solution.

\section{Inhibition of $\mathrm{H}$. pylori urease using spring water}

To test the inhibitory activity of $H$. pylori urease, H. pylori was incubated in three different BHI media (normal BHI, BHIDSW and BHIBSW). Then, each liquid medium was inoculated with $10^{8}$ cells $/ \mathrm{ml}$ of $H$. pylori and after 3 days of incubation, the cells were harvested by centrifugation. The supernatant and the cell pellets were used as respective enzyme sources. The cell pellets were then suspended in PBS (the volume of the PBS was the same as the volume of the culture broth), and were then disrupted by $30 \mathrm{~s}$ bursts from a Sonifier at $30 \mathrm{~W}$ for a $50 \%$ cycle followed by centrifugation at $4{ }^{\circ} \mathrm{C}$, and the supernatant was used as an enzyme solution. The same volume of $10 \%$ urea solution and either culture broth (supernatant) or sonicated supernatant were incubated at room temperature for 90 min. During incubation, the produced ammonia was spectrophotometrically assayed using a Hitachi 7600 (Tokyo, Japan) at 30 min intervals. PBS was used as the control instead of the $10 \%$ urea solution.

\section{Effect of pH on the urease enzyme activity}

To confirm the effect of $\mathrm{pH}$ on the urease activity, urease assay was conducted in two different $\mathrm{pH}$ system ( $\mathrm{pH} 7.4$ and $\mathrm{pH}$ 9.0). $15 \mu \mathrm{l}$ of Jack bean urease $(1 \mu \mathrm{g} / \mathrm{ml}$ in $0.1 \mathrm{M}$ phosphate buffer, $\mathrm{pH} 7.4)$ was added to $1 \mathrm{ml}$ of two different $0.5 \mathrm{M}$ urea solutions $(0.5 \mathrm{M}$ urea solution were prepared with $\mathrm{pH} 7.4$ and 9.0 PBS) by incubation at room temperature for $90 \mathrm{~min}$. During incubation, the produced ammonia was spectrophotometrically assayed using a Hitachi 7600 (Tokyo, Japan) in 30 min intervals. PBS was used as a control instead of a urea solution.

\section{Western blot analysis of $\mathrm{H}$. pylori urease}

To test the effect of SW on the synthesis of urease, western blot analysis was conducted to detect urease A and B 
subunits. Anti-rabbit urease $\alpha$ (B-234) (sc-21016, 1:1000; SantaCruz Biotechnology, Inc., Santa Cruz, CA, USA) and Anti-rabbit urease $\beta$ (B-300) (sc-22742, 1:1000; SantaCruz Biotechnology, Inc., Santa Cruz, CA, USA) were used as the primary antibodies, and Anti-mouse H. pylori OMP (6631) (sc-69935, 1:1000; SantaCruz Biotechnology, Inc., Santa Cruz, CA,USA) was used as the control protein. Goat anti-rabbit IgG-horseradish peroxidase (HRP) conjugate (170-6515, 1:2000; Bio-Rad) and Goat anti-mouse IgG-horseradish peroxidase (HRP) conjugate (170-6516,1;2000; Bio-Rad) were used as secondary antibodies.

After 3 days of incubating H. pylori in three different BHI media (normal BHI, BHIDSW and BHIBSW), H. pylori cells were harvested. The cells were suspended in $1 \mathrm{~mL}$ of PRO-PREPTM protein Extraction Solution (17081, iNtRON Biotechnology, Korea), and incubated for $30 \mathrm{~min}$ at $4{ }^{\circ} \mathrm{C}$. After centrifugation at $12,000 \mathrm{rpm}$ for $30 \mathrm{~min}$ at $4{ }^{\circ} \mathrm{C}$, the concentrations of protein in the supernatants were determined via a BCA Protein Assay Kit (\#23227, Pierce, Rockford, IL). Forty $\mu \mathrm{g}$ of total protein were electrophoresed on 8-12\% SDS-PAGE and transferred to a nitrocellulose membrane (Protran BA85, Whatman/ GE Healthcare, PA, USA) via Transfer System (Bio-Rad, CA, USA). Nonspecific binding was inhibited by incubation in 5\% non-fat dry milk [TBST $(0.05 \%$ Tween-20 in TBS)]. After overnight incubation at $4{ }^{\circ} \mathrm{C}$ in a TBST solution $(0.05 \%$ Tween-20 in TBS), the membrane was washed three times with TBST solution then incubated with horse radish peroxidase (HRP), conjugated goat anti-rabbit IgG (170-6515, 1:2000; Bio-Rad), and antimouse (170-6516,1;2000; Bio-Rad) for $1 \mathrm{hr}$ and analyzed using highly cooled CCD cameras (AE9300-Ez-CaptureMG) and a densitograph software CS analyzer (ver3.0) (ATTO, Tokyo, Japan).

\section{Results}

\section{Hydrochemical analysis of Dukku and Baekam springwater}

The $\mathrm{pH}$ of the Dukku SW (DSW) was 8.90, and that of the Baekam SW (BSW) was 9.54. Both SW samples contained $\mathrm{Si}, \mathrm{Na}, \mathrm{K}, \mathrm{AL}, \mathrm{Ca}, \mathrm{Mg}, \mathrm{F}, \mathrm{Cl}, \mathrm{S}, \mathrm{Sr}$, and carbonate ion (Table 1).

Table 1: Hydrochemical analysis of Dukku and Baekam springwater

\begin{tabular}{|c|c|c|}
\hline & DSW & BSW \\
\hline Temperature $\left({ }^{\circ} \mathrm{C}\right)$ & 30.5 & 41.6 \\
\hline $\mathrm{pH}$ & 8.90 & 9.54 \\
\hline TDS (mg/L) & 144 & 144 \\
\hline Alkalinity (mg/L) & 1.36 & 1.54 \\
\hline $\mathrm{Si}(\mathrm{mg} / \mathrm{L})$ & 14.23 & 20.48 \\
\hline $\mathrm{Na}(\mathrm{mg} / \mathrm{L})$ & 106.4 & 45.4 \\
\hline $\mathrm{K}(\mathrm{mg} / \mathrm{L})$ & 0.10 & 0.07 \\
\hline $\mathrm{Al}(\mathrm{mg} / \mathrm{L})$ & 0.17 & 0.08 \\
\hline $\mathrm{Ca}(\mathrm{mg} / \mathrm{L})$ & 3.06 & 1.83 \\
\hline $\operatorname{Mg}(\mathrm{mg} / \mathrm{L})$ & $\mathrm{Nd}$ & $\mathrm{Nd}$ \\
\hline $\mathrm{Fe}(\mathrm{mg} / \mathrm{L})$ & $\mathrm{Nd}$ & $\mathrm{Nd}$ \\
\hline $\mathrm{Zn}(\mathrm{mg} / \mathrm{L})$ & $\mathrm{Nd}$ & $\mathrm{Nd}$ \\
\hline $\mathrm{Ba}(\mathrm{mg} / \mathrm{L})$ & $\mathrm{Nd}$ & $\mathrm{Nd}$ \\
\hline $\mathrm{F}(\mathrm{mg} / \mathrm{L})$ & 13.63 & 3.23 \\
\hline $\mathrm{Cl}(\mathrm{mg} / \mathrm{L})$ & 5.07 & 8.71 \\
\hline $\mathrm{Br}(\mathrm{mg} / \mathrm{L})$ & $\mathrm{Nd}$ & $\mathrm{Nd}$ \\
\hline $\mathrm{NO}_{3}^{-}(\mathrm{mg} / \mathrm{L})$ & 0.32 & $\mathrm{Nd}$ \\
\hline $\mathrm{SO}_{4}^{2-}(\mathrm{mg} / \mathrm{L})$ & 6.23 & 15.72 \\
\hline $\mathrm{HCO}_{3}^{-}(\mathrm{mg} / \mathrm{L})$ & 82.97 & 93.95 \\
\hline $\mathrm{Sr}(\mathrm{mg} / \mathrm{L})$ & 0.03 & 0.08 \\
\hline
\end{tabular}

\section{The effect of springwater on the growth of $\mathrm{H}$. pylori}

To test the effect of the growth inhibition by the SW, H. pylori cells were incubated in normal BHI, BHIDSW and BHIBSW, respectively. As shown in Table 2, there were no significant differences in growth, depending on the media. Therefore, SW showed no inhibitory activity against proliferation of $H$. pylori. 
Table 2: Inhibitory effects of Dukku and Baekam Springwater against H. pylori Proliferation.

\begin{tabular}{lll}
\hline $\log _{10} C F U / m L($ mean \pm SD,$n=3)$ & \\
\hline Control & BHIDSW $^{\mathrm{a}}$ & BHIBSW $^{\mathrm{b}}$ \\
$8.23 \pm 0.83$ & $8.2 .1 \pm 0.23$ & $8.11 \pm 0.12$ \\
\hline
\end{tabular}

a: BHIDSW, BHI media prepared with Dukku spring water

b: BHIBSW, BHI media prepared with Baekam spring water

\section{Inhibition of Jack bean Urease by springwater}

To test the inhibition of Jack bean urease activity by two different samples of SW, urease assays were performed. In the presence of two samples of SW, $50 \%$ of urease activity was decreased. In the control group, the concentration of ammonia that was produced by Jack bean urease was $45,000 \mu \mathrm{g} / \mathrm{ml}$, but in the presence of the two samples of SW, the concentration of ammonia produced by jack bean urease was only $20,000 \mu \mathrm{g} / \mathrm{ml}$ (Fig. 1).

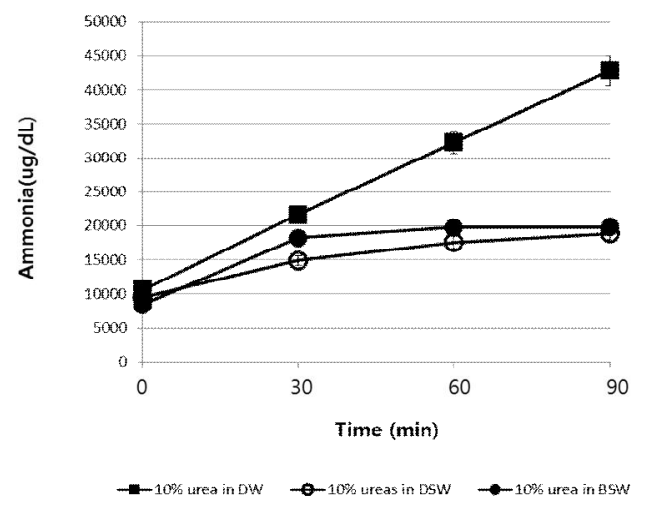

Figure 1: Inhibition of Jack bean urease by Dukku Springwater and Baekam Springwater.

DSW: Dukku Springwater, BSW: Baekam Springwater

\section{Inhibition of $H$. pylori urease by springwater}

To determine the inhibitory effect of two samples of SW against $H$. pylori urease, $H$. pylori was cultured in media prepared with BHIDSW and with BHIBSW. Both the culture broth and the cell pellets showed inhibitory activity against $H$. pylori urease. In the case of the control, the concentration of ammonia after 90 min was 16,000 $\mu \mathrm{g} / \mathrm{dl}$. In the case of the cell pellet, however, the concentration of ammonia after $90 \mathrm{~min}$ was 4,000 $\mu \mathrm{g} / \mathrm{dl}$. This result shows that the production of ammonia was decreased by about $75 \%$ in the presence of SW (Fig. 2).

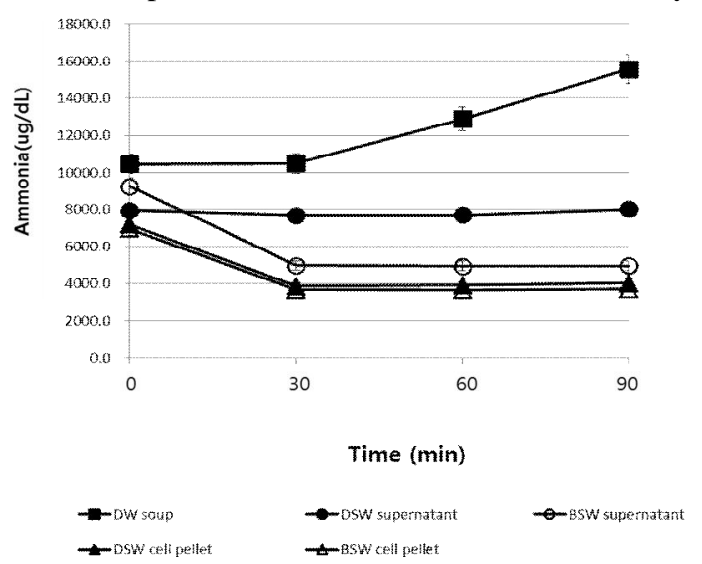

Figure 2: Inhibition of Helicobacter pylori urease by Dukku Springwater and Baekam Springwater.

DW: BHI prepared with Distilled water, DSW: BHI prepared with Dukku Springwater, BSW: BHI prepared with Baekam Springwater

\section{Western blot analysis of $\mathrm{H}$. pylori urease}

Western blot analysis was performed to determine the influence of SW on the synthesis of UreA and UreB 
proteins. Western blot analysis showed that similar amounts of UreA and UreB were synthesized, depending on the culture medium prepared with SW (Figs. 3, 4).

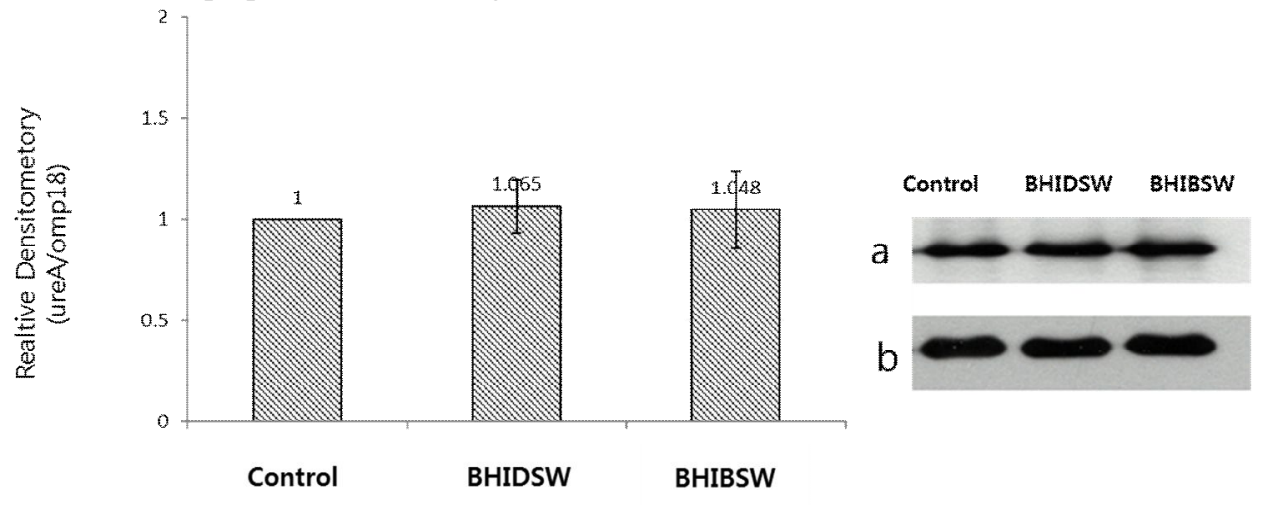

Fig. 3 Western blot analysis of Helicobacter pylori urease A subunit

Control: Cells were cultured in normal BHI media; BHDSW: cells were cultured in BHI media prepared with Dukku spring water; BHIBSW: cells were cultured in BHI media prepared with Baekam spring water a;omp18, b; ureA

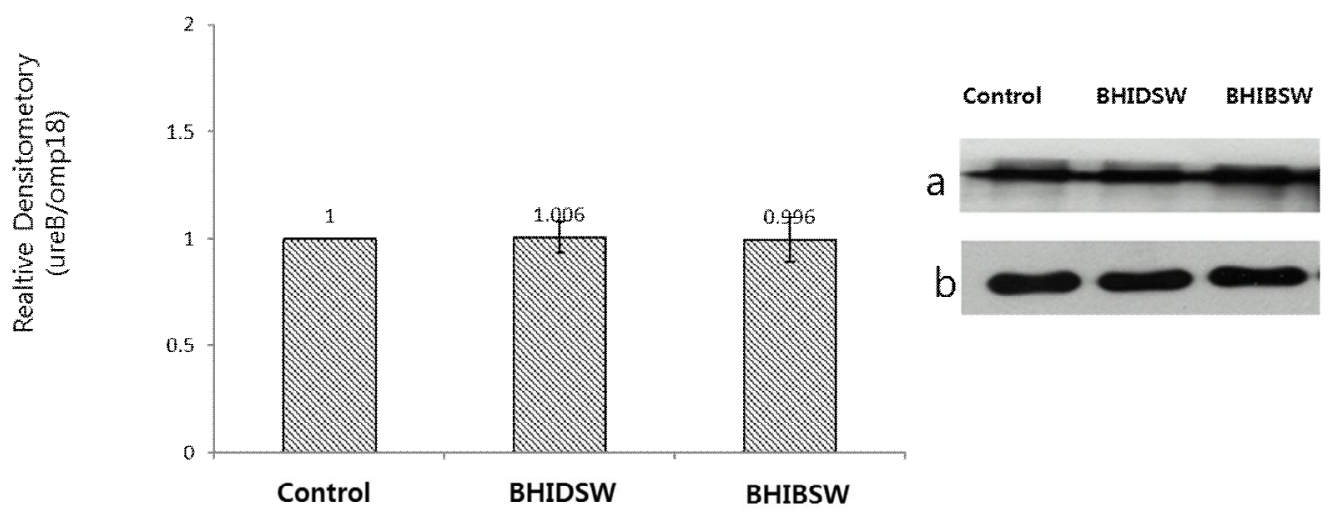

Fig. 4 Western blot analysis of Helicobacter pyloriurease B subunit Control: Cells were cultured in normal BHI media; BHIDSW: cells were cultured in BHI media prepared with Dukku spring water; BHIBSW: cells were cultured in BHI media prepared with Baekam spring water.a;opm18, b; ureB

\section{Discussion}

Urease is a virulence factor that is necessary for the colonization of $H$. pylori, which makes it a major target for drug development. To survive in a strong acidic environment, it is necessary for $H$. pylori to degrade urea via urease to produce the ammonia that will neutralize the acidic environment (Marshall et al., 1990). Therefore, the ureaseproducing ability of $H$. pylori is very important for colonization. By mainly locating in the antrum, $H$. pylori weakens the $\mathrm{pH}$ sensing in the antrum and degrades the phospholipids of the host epithelial cells via the ammonia produced by urease (Zhang et al., 2005). An alternative to antibiotic remedies, the inhibition of $H$. pylori urease that is described above can solve the problem of gastric mucosal damage that is caused by the colonization of $H$. pylori. Many recent studies have focused on the inhibitors of urease, and the aim of the present study was to investigate the effect of SW on the urease activity of $H$. pylori. When we tested the antibacterial activity of SW against $H$. pylori, there was no significant difference in the numbers of bacteria between media made of spring water and normal culture medium (Table 1). The inhibition of H. pylori and Jack bean urease by SW, however, recorded maximum reductions of 75 and $50 \%$, respectively (Figs. 1, 2). According to the hydro-chemical analysis of spring waters, they have alkaline $\mathrm{pH}(8.90$ and 9.54). Therefore, it is necessary to confirm this inhibitory activity may attribute to $\mathrm{pH}$ effect. However, when we 
tested the $\mathrm{pH}$ effect, there were no differences in enzyme activity between $\mathrm{pH} 7.4$ and $\mathrm{pH} 9.0$ (data not shown). Future in vivo and human study will be necessary to confirm the effect of SW on the urease activity of $H$. pylori inhabiting gastric mucosa. There have been few reports about the effects of $H$. pylori by SW, particularly with respect to the urease enzyme. Based on our data, it is conceivable that the ordinary consumption of SW may prevent the colonization of $H$. pylori by inhibiting urease in the human stomach.

Urease is a metalloenzyme containing nickel ion (Ni) essential for its activity (Benanti and Chivers 2009). Urease without Ni shows no activity and many metal ions, including copper, competitively inhibit the entry of Ni into protein (Hausinger, 1987; Todd and Hausinger, 1989; Park and Hausinger, 1996; Amtul et al., 2002). A large amount of Si dissolved in both the samples of SW might have inhibited the enzyme activity by competitively binding to the binding site of Ni (Kind et al., 1954; Amin et al., 2012). Some amount of Si is also dissolved in two SW (Table 1). And many other types of metal ions such as $\mathrm{Ag}, \mathrm{Hg}, \mathrm{Mn}, \mathrm{Pd}, \mathrm{Co}$ and $\mathrm{Cd}$, are also known to inhibit urease activity (Kumar and Kayastha, 2010; Amin et al., 2010; Amin et al., 2012; Dong et al., 2012; Dong et al., 2013;). As described above, the two samples of SW contained various mineral ions (Table1). The exact mechanism of urease activity inhibition by the SW used in this study is still unknown whether Si or other metal ions in the main one for contributing action.

In future, it is necessary to investigate the exact mechanism and to establish the main one that plays a role in the SW. According to western blot analysis, the enzyme production of $H$. pylori was not inhibited, but its function was affected because the band intensities of UreA and UreB from different media showed similar patterns (Fig. 3 and 4 ).

Up to now, drinking of SW has been used to treat gastritis, peptic ulcer and functional disorder, because SW can increase blood flow, increase or inhibit gastric juices, depending on the type of SW, and inhibit gastric emptying (Petrakova, 2001; Bertoni et al., 2002;). Sodium bicarbonate spring water is usually recommended for the treatment of gastric disorders because it can neutralize gastric acid and inhibit stomach cramps. Carbon dioxide SW, which is known to increase gastric mucosal blood flow, has been used to treat chronic gastritis (Razumov et al., 2009). However, it has never been known whether these therapeutic effects of SW are related to an inhibition of the bacterial urease activity of $H$. pylori or not. Moreover, whether this effect is due simply to the effects of various minerals or to urease inhibition is still unknown, and further study is necessary. In addition, the SW used in this study has been ingested for many years by local residents living in proximity to the hot spring. Therefore, it is necessary to conduct a populationbased study about the rate of $H$. pylori infection and urease activity among the people drinking this SW.

In conclusion, this study used SW that contains various metal ions and is thought to be effective for the treatment of various upper gastrointestinal disorders by inhibiting urease, which is one of the virulence factors of $H$. pylori.

\section{Acknowledgements}

The authors thank Jee Eun Oh for assisting with the research.

\section{Funding}

This work was supported by the Korean Academy of Hot Spring.

\section{Authors' contributions}

Designed the study: HK Lee, JW Kim and HS Chae. Carried the experiments: SS Choi, HK Kim, JH Yu, HH Choi, HK Kim and SW Kim. Wrote the manuscript: SS Choi, JH Yu, HH Choi and HS Chae. All authors read and approved the manuscript.

Competing interests: The authors declare that they have no competing interests.

\section{References}

1. Amin, M., Iqbal, M. S., Hughes, R. W., Khan, S. A., Reynolds, P. A., Enne, V.I., Sajjiad-ur-Rhaman, and Mirza, A. S. (2010). Mechanochemical synthesis and in vitro anti-Helicobacter pylori and uresase inhibitory activities of novel zinc(II)-famotidine complex. Journal of Enzyme Inhibition and Medicinal Chemistry; 25(3): 383-390.

2. Amin, M., Anwar, F., Janjua, M. R., Oqbal, M. A. and Rashid, U. (2012). Green synthesis of silver nanoparticles through reduction with Solanum xanthocarpum L. berry extract: characterization, antimicrobial and urease inhibitory activities against Helicobacter pylori. International Journal of Molecular Sciences; 13(8):9923-9941.

3. Amtul, Z., Rahman A. U., Siddiqui, R. A. and Choudhary, M. I. (2002). Chemistry and mechanism of urease inhibition. Current Medicinal Chemistry; 9(14):1323-1348.

4. Benanti, E. L. and Chivers, P. T. (2009). An intact urease assembly pathway is required to compete with NikR for nickel ions in Helicobacter pylori. Journal of Bacteriology; 191(7):2405-2408.

5. Bertoni, M., Olivieri, F., Manghetti, M., Boccolini, E., Bellomini, M. G., Blandizzi, C., Bonino, F. and Del Tacca, M. (2002). Effects of a bicarbonate-alkaline mineral water on gastric functions and functional dyspepsia: a preclinical and clinical study. Pharmacological Research; 46(6): 525-531. 
6. Dong, X., Guo, T., Li, Y., Cui, Y. and Wang, Q. (2013). Synthesis, structure and urease inhibition studies of Schiff base copper (II) complexes with planar four-coordinate copper (II) centers. Journal of Inorganic Biochemistry; 127: 82-89.

7. Dong, X., Li, Y., Li, Z., Cui, Y. and Zhu, H. (2012). Synthesis, structures and urease inhibition studies of copper (II) and nickel (II) complexes with bidentate N,O-donor Schiff base ligands. Journal of Inorganic Biochemistry; 108: $22-29$.

8. Dunn, B. E. (1993). Pathogenic mechanism of Helicobacter pylori. Gastroenterology Clinics of North America; 22 (1):43-57.

9. Graham, D. Y. and Yamaoka, Y. (2000). Disease-specific Helicobacter pylori virulence factors: the unfulfilled promise. Helicobacter; 5: S3-S9.

10. Hausinger, R. P. (1987). Nickel utilization by microorganisms. Microbiological Reviews; 51(1):22-42.

11. Todd, M. J. and Hausinger, R. P. (1989). Competitive inhibitors of Klebsiella aerogenes urease. Mechanisms of interaction with the nickel active site. Journal of Biological Chemistry; 264(27):15835-15842.

12. Khan, K. M., Iqbal, S., Lodhi, M. A., Maharvi, G. M., Ullah, Z., Choudhary, M. I., Rahman, A. U. and Perveen, S. (2004). Biscoumarin: new class of urease inhibitors; economical synthesis and activity. Bioorganic and Medicinal Chemistry; 12(8):1963-1968.

13. Kim, J. H., Kim, H. Y., Kim, N. Y., Kim, S. W., Kim, J. G., Kim, J. J., Roe, I. H., Seo, J. K., Sim, J. G., Ahn, H., Yoon, B. C., Lee, S. W., Lee, Y. C., Chung, I. S., Jung, H. Y., Hong, W.S. and Choi, K. W. (2001). Seroepidemiological study of Helicobacter pylori infection in asymptomatic people in South Korea. Journal of Gastroenterolopgy and Hepatology; 16(9):969-975.

14. Kind, P. R., King, E. J., Pash, V., Roman, W. and Schmidt, E. (1954). Inhibition of enzymes by silicic acid. Biochemical Journal; 16:56(325th Meeting): xlv.

15. Kosikowska, P. and Berlicki, Ł. (2011). Urease inhibitors as potential drugs for gastric and urinary tract infections: a patent review. Expert Opinion on Therapeutic Patents; 21(6):945-957.

16. Kumar, S. and Kayastha, A. M. (2010). Inhibition studies of soybean (Glycine max) urease with heavy metals, sodium salts of mineral acids, boric acid, and boronic acids. Journal of Enzyme Inhibition and Medicinal Chemistry; 25(5): 646-652.

17. Lee, Y. B., Lee, J. Y., Lee, H. J., Yun, S. T., Lee, J. T., Lim, H. J., Yoo, D. S., Woo, S. Y. and Kim, J. W. (2014). Immunomodulatory effects of balneotherapy with Hae-Un-Dae thermal water on imiquimod-induces psoriasis-like murine model. Annals of Dermatology; 26 (2): 221-230.

18. Lodhi, M. A., Shams, S., Choudhary, M. I., Lodhi, A., UI-Haq, Z., Jalil, S., Nawaz, S. A., Khan, K. M., Iqbal, S. and Rahman, A. U. (2014). Structural basis of binding and rationale for the potent urease inhibitory activity of biscoumarins. Biomed Research International Journal; 2014:935039.

19. Marshall, B. J., Barrett, L. J., Prakash, C., McCallum, R. W. and Guerrant, R. L. (1990). Urea protects Helicobacter (Campylobacter) pylori from the bactericidal effect of acid. Gastroenterology; 99 (93): 697-702.

20. Mobley, H. L., Hu, H. T. and Foxal, P. A. (1991). Helicobacter pylori urease: properties and role in pathogenesis. Scandinavian Journal of Gastroenterology; Suppl. 187: 39-46.

21. Osaki, T., Mabe, K., Hanawa, T. and Kamiya, S. (2008). Urease-positive bacteria in the stomach induce a falsepositive reaction in a urea breath test for diagnosis of Helicobacter pylori infection. Journal of Medical Microbiology; 57: 814-819.

22. Park, I. S. and Hausinger, R. P. (1996). Metal ion interaction with urease and UreD-urease apoproteins. Biochemistry; 35(16):5345-5352.

23. Petrakova, V. S. (2001). Possibility of using intensive peloid balneotherapy on duodenal ulcer patients. Vopr Kurortol Fizioter Lech Fiz Kult; 5:20-23.

24. Razumov, A. N., Surkov, N. V., Frolkov, V. K. and Ziniakov, N. T. (2009). Therapeutic and preventive effects of sulfate-chloride-sodium mineral water in experimental peptic ulcer. Vopr Kurortol Fizioter Lech Fiz Kult; 3: 22 -25.

25. Yu, X. D., Xie, J. H., Wang, Y. H., Li, Y. C., Mo, Z. Z., Zheng, Y. F., Su, J. Y., Liang, Y. E., Liang, J. Z., Su, Z. R. and Huang, P. (2015). Selective antibacterial activity of patchouli alcohol against Helicobacter pylori based on inhibition of urease. Phytotherapy Research; 29(1):67-72.

26. Zaborska, W., Krajewska, B. and Olech, Z. (2004). Heavy metal ions inhibition of jack bean urease: potential for rapid contaminant probing. Journal of Enzyme Inhibition and Medicinal Chemistry; 19(1): 65-69.

27. Zhang, C., Yamade, N., Wu, Y. L., Wen, M., Matsuhisa, T. and Matsukura, N. (2005). Comparison of Helicobacter pylori infection and gastric mucosal histological features of gastric ulcer patients with chronic gastritis patients. World Journal of Gastroenterology; 11(7):976-981. 